\title{
Mide Kanserinde Pozitif Lenf Nodu Oranının Prognostik Önemi
}

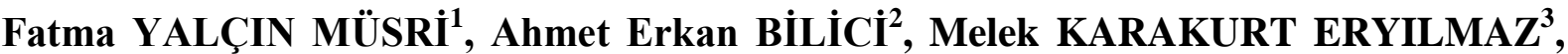 \\ Özgür Cem MÜSRİ ${ }^{4}$, Gökhan TAZEGÜL ${ }^{5}$, Selver IŞIK ${ }^{6}$, Muhammed Ali KAPLAN ${ }^{7}$
}

1 Medical Park Hastanesi, Tıbbi Onkoloji Kliniği, Batman.

2 Erzurum Bölge Eğitim ve Araştırma Hastanesi, Tıbbi Patoloji Bölümü, Erzurum.

3 Necmettin Erbakan Üniversitesi Tıp Fakültesi, Tıbbi Onkoloji Anabilim Dalı, Konya.

4 Medical Park Hastanesi, Genel Cerrahi Kliniği, Batman.

5 Ankara Polatlı Duatepe Devlet Hastanesi, İç Hastalıkları Kliniği, Ankara.

6 Erzurum Bölge Eğitim ve Araştırma Hastanesi, Tıbbi Onkoloji Kliniği, Erzurum.

7 Dicle Üniversitesi Tıp Fakültesi, Tıbbi Onkoloji Anabilim Dalı, Diyarbakır.

\section{ÖZET}

Bu çalışmada, evre 1-3 gastrik karsinomda (GK) metastatik lenf nodlarının toplam çıkarılan lenf nodu sayısına oranının (LNO) prognostik önemini değerlendirmeyi amaçladık. 2012-2019 yılları arasında opere edilen evre 1-3 GK'lı toplam 233 hasta retrospektif olarak değerlendirildi. Sağkalım eğrileri Kaplan-Meier yöntemi kullanılarak oluşturuldu. Medyan metastatik ve disseke lenf nodu sayısı sırasıyla 5 ve 27 idi, ortalama LNO 0.1 idi. Hastalar LNO $<0.1$ ve $\geq 0.1$ olanlar olmak üzere iki gruba ayrıldı. Medyan $L N O<0.1$ ve $\geq 0.1$ olan hastalarda medyan genel sağkalım 26.9 ay ve 76 ay idi $(\mathrm{p}<0.001)$. Tek değisskenli analizde cinsiyet, lenfovasküler invazyon (LVI) ve perinöral invazyon (PNI) medyan genel sağkalımda anlamlı bulundu (sırasıyla $\mathrm{p}=0.043,<0.001$ ve $<0.001$ ). LNO ve LVİ, çok değişkenli analizde genel sağkalımın bağımsız prediktörleri olarak saptandı (sırasıyla p $<0.01$ ve 0.02 ). GK hastalarında artan LNO, opere edilen hastalarda azalmış genel sağkalım açısından prognostik bir öneme sahiptir. Bu nedenle, LNO, yetersiz lenf nodu diseksiyonu veya D1 diseksiyonu olan hastalarda patolojik nodal sınıflandırma yerine kullanılabilir.

Anahtar Kelimeler: Mide kanseri. Lenf nodu oranı. Genel sağkalım.

Prognostic Importance of the Positive Lymph Node Ratio in the Gastric Cancer

\section{ABSTRACT}

Herein, we aimed to evaluate the prognostic significance of the ratio of metastatic lymph nodes to the total number of removed lymph nodes (LNR) in Stage 1-3 operated gastric carcinoma (GC). A total of 233 patients with stage 1-3 GC operated between 2012 and 2019 were retrospectively evaluated. Survival curves were constructed using the Kaplan-Meier method. The median number of metastatic and dissected lymph nodes were 5 and 27, respectively, with a median LNR of 0.1 . Patients were categorized into two groups as those with a LNR $<0.1$ and $\geq 0.1$. Median OS in patients with a median LNR of $<0.1$ and $\geq 0.1$ were 76 vs. 26.9 months $(\mathrm{p}<0.001)$. In univariate analysis gender, lymphovascular invasion (LVI), and perineural invasion (PNI) were found to be significant predictors of median OS ( $\mathrm{p}=0.043,<0.001$ and $<0.001$, respectively). LNR and LVI emerged as independent predictors of OS in the multivariate analyses $(\mathrm{p}<0.01$ and 0.02 , respectively). LNR has prognostic significance for OS in operated GC patients where increasing LNR is associated with reduced overall survival. Thus, LNR may be used as a substitute for pathological nodal classification in patients with insufficient lymph node dissection or D1 dissection.

Key Words: Gastric cancer. Lymph node ratio. Overall survival.

Geliş Tarihi: 28.Haziran.2020

Kabul Tarihi: 19.Ağustos.2020

Dr. Fatma YALÇIN MÜSRİ

Medical Park Hastanesi

Tıbbi Onkoloji Kliniği,

Ziya Gökalp, Atatürk Blv. No: 141,

Batman.

Tel: 05057134247

E-posta: yalcinfatma@hotmail.com
Yazarların ORCID ID Bilgisi:

Fatma YALÇIN MÜSRI: 0000-0003-2502-3797

Ahmet Erkan BíLiCi: 0000-0003-4458-0791

Melek KARAKURT ERYILMAZ: 0000-0003-2597-5931

Özgür Cem MÜSRi: 0000-0002-3104-6509

Gökhan TAZEGÜL: 0000-0002-0737-9450

Selver IŞIK: 0000-0002-2726-1740

Muhammed Ali KAPLAN: 0000-0003-0882-0524 
Gastrik kanser (GK) dünyada en sık görülen beşinci, kansere bağlı ölümlerde üçüncü sıradadır ${ }^{1}$. GK insidansı ve mortalitesi giderek azalsa da 5 yıllık sağkalım oranları \%20-25 civarındadır ${ }^{2}$. Sağkalımı belirleyen en önemli faktör evredir. İki ana evreleme sisteminden, Japon Gastrik Kanser Araştırma Derneği (JRSGC) tarafından geliştirilen Japon Gastrik Karsinom Sınıflandırması'nda (JCGC), bölgesel lenf nodları primer tümöre göre pozitif lenf nodlarının konumuna göre 3 gruba ayr1lır (N1 - N3). UICC (Uluslararas1 Kanser Kontrol Birliği) / AJCC (Amerikan Kanser Ortak Komitesi) tarafından yaygın olarak önerilen diğer sistem ise yaygın olarak tümör-düğüm-metastaz (TNM) evreleme sistemi olarak bilinir ${ }^{3,4}$. TNM en yaygın olarak kullanılan evreleme sistemi olup, nodal sinıflandırma metastatik lenf nodu sayısına göre yapılır. Metastatik lenf nodu olmayan pN0, 1-2 metastatik lenf nodu pN1, 3-6 metastatik lenf nodu pN2, 7 ve üstü metastatik lenf nodu N3 olarak tanımlanmaktadır. Bununla birlikte, Bununla birlikte, UICC / AJCC TNM sınıflandırması, yeterli $\mathrm{N}$ evrelemesi için en az 15 lenf nodunun değerlendirilmesi gereklidir.

Pozitif lenf nodlarının toplam çıkarılan lenf nodu sayısına oranı olarak tanımlanan metastatik lenf nodu oranının (LNO), küratif rezeksiyon uygulanan hastalarda gastrik karsinomlu hastalarda yeni bir prognostik belirteç olabileceğini öne sürülmektedir ${ }^{5-12}$. Ayrıca, LNO'nun iki ana evreleme sistemine dayanan lokalizasyon ve sayı bazlı nod evrelemesinden üstün olduğu, GK'da bağımsız bir prognostik gösterge olduğu bildirilmiştir ${ }^{12-14}$.

$\mathrm{Bu}$ çalışmada amacımız, mevcut evreleme sistemlerinde nodal sınıflamanın yeterliliği üzerine tartışmalar sürerken, opere edilen GK hastalarında LNO'nun prognostik önemini değerlendirmektir.

\section{Gereç ve Yöntem}

Bu çalışma için Sağlık Bilimleri Üniversitesi Erzurum Bölge Eğitim ve Araştırma Hastanesi Klinik Araştırmalar Etik Kurulu'ndan onay alınmıştır (Onay tarih: 20.05.2020, Onay sayıs1: 37732058-514.10).

Sağlık Bilimleri Üniversitesi Erzurum Bölge Eğitim ve Araştırma Hastanesi'nde 2012-2019 yılları arasında Evre 1-3 GK nedeniyle opere edilen toplam 233 hasta bu retrospektif çalışmaya alındı. Çalışmaya, tüm hastaların endoskopik biyopsi ile histopatolojik olarak GK tanısı doğrulanmış, küratif gastrik cerrahi ve lenf nodu diseksiyonu yapılmış, cerrahi sınır R0 (makroskopik rezidüel tümör ve cerrahi sinırda karsinom hücresi olmadan tümörün tam çıkarılması) olan hastalar dahil edildi. Tanı anı metastatik hastalık saptanan hastalar çalışmaya dahil edilmedi. Patolojik evreleme UICC/AJCC TNM 8. versiyona göre yapıldı. Hastaların tanı yaşı, cinsiyeti, operasyonun tipi (total vs. subtotal gastrektomi), tümör yerleşimi, histolojik tipi ve derecesi, lenfovasküler invazyon (LVİ) ve perinöral invazyon (PNI), çıkarılan ve metastatik lenf nodu sayısı ile adjuvan tedavi tipi kaydedildi. Lenf nodu oranı (LNO), tümör pozitif lenf nodunun cerrahi olarak çıkarılan lenf noduna oranı olarak tanımlandı ve medyan değerler kaydedildi.

\section{Istatistiksel Analizler}

İstatistiksel analizde SPSS 22.0 kullanıldı. Tanımlayıcı istatistikler oranlar ve medyan olarak hesaplandı. Sağkalım analizi için Kaplan-Meier yöntemi kullanıldı. Genel sağkalım (GS), tedavinin başlamasından herhangi bir nedenden ölene kadar geçen süre olarak tanımlandı. Diğer değişkenler arasında GS arasındaki ilişkiyi tanımlamak için tek değişkenli ve çok değişkenli regresyon analizleri Backwards metodu kullanılarak yapıldı. İstatistiki anlamlılık sınırı $\mathrm{p}<0.05$ kabul edildi.

\section{Bulgular}

Opere evre 1-3 GK'lı 233 hasta çalışmaya alındı. Hastaların \%6.4' ü evre 1,\%15'i evre 2 ve \%78.5'i evre 3 idi. Hastaların \%32.6'sı kadın, \%67.4'ü erkek idi. Hastaların medyan yaşı 61 idi. Medyan disseke edilen lenf nodu sayıs1 27 (3-69) ve medyan tutulu lenf nodu sayısı 5 (0-57) saptandı. TNM'ye göre $\mathrm{N} 0, \mathrm{~N} 1, \mathrm{~N} 2$ ve N3 hasta say1s1 siras1 ile 79, 90, 41 ve 23 idi (surasiyla \%33.9, \%38.6, \%17.6, \%9.9). LNO medyan değeri 0.1 saptandi. Hastalar, LNO $<0.1$ ve $\mathrm{LNO} \geq 0.1$ olarak kategorize edildi. Hastaların 181 'i (\%77.7) adjuvan kemoterapi, 143'ü (\%61.4) adjuvan radyoterapi, 44'ü (\%18.9) neoadjuvan kemoterapi almıştı. Sekiz hasta (\%3.4'ü) ise neoadjuvan kemoradyoterapi sonrası opere edilmişti. Hastaların çoğunun tümör yerleşimi kardiya ve korpustu ve ana histoloji adenokarsinomdu. Hastaların çoğunluğuna total gastrektomi yapılmıştı (Tablo I).

233 hastanın medyan genel sağkalımı 48.3 ay olarak izlendi (Şekil 1). TNM'nin patolojik lenf nodu sınıflamasına göre, hastaların genel sağkalımı (GS) analiz edildiğinde, N0, N1, N2 ve N3 hastalıkta medyan GS sirası ile $132,43,22$ ve 22 ay olarak hesapland $(\mathrm{p}=0,0001$, Şekil 2). LNO $<0.1$ olan grupta, $\geq 0.1$ olan gruba göre medyan GS uzundu (76 aya karşın 26.9 ay, $\mathrm{p}<0.001$, Şekil 3). Ayrıca, erkek cinsiyet (kadın/erkek; 132.4 ay/39.2 ay, p=0.043), LVİ olan (Var/Yok; 31.5 ay/76 ay, $\mathrm{p}<0.001$ ) ve PNİ olan (Var/Yok; 31.5 ay/76 ay, $\mathrm{p}<0.001$ ) hastalar daha kötü medyan GS'ye sahipti (Tablo II). Multivariate analizde LNO'nun $\geq 0.1$ olmas1 medyan GS için anlamlı bağımsız kötü prognostik bir faktördü ( $<<0.001$, Tablo III). Ayrıca LVİ varlığı da medyan GS için anlamlı kötü prognostik faktördü $(\mathrm{p}=0.02)$. 
Mide Kanserinde Pozitif Lenf Nodu Oranı

Tablo I. Çalışmaya alınan hastaların klinik ve patolojik özellikleri

\begin{tabular}{|c|c|}
\hline & $n(\%)$ \\
\hline $\begin{array}{l}\text { Cinsiyet } \\
\text { Kadın } \\
\text { Erkek }\end{array}$ & $\begin{array}{l}76(32.6) \\
157(67.4)\end{array}$ \\
\hline $\begin{array}{l}\text { Evre } \\
\text { I } \\
\text { II } \\
\text { III }\end{array}$ & \begin{tabular}{|l}
$15(6.4)$ \\
$35(15)$ \\
$183(78.5)$
\end{tabular} \\
\hline $\begin{array}{l}\text { Tümör lokalizasyonu } \\
\text { Kardiya } \\
\text { Korpus } \\
\text { Antropilorik } \\
\text { Diffüz }\end{array}$ & $\begin{array}{l}107(45.9) \\
78(33.5) \\
43(18.5) \\
5(2.1)\end{array}$ \\
\hline $\begin{array}{l}\text { Cerrahi tipi } \\
\text { Total } \\
\text { Subtotal }\end{array}$ & $\begin{array}{l}175 \text { (75.1) } \\
58(24.9)\end{array}$ \\
\hline $\begin{array}{l}\text { Histoloji } \\
\text { Adenokanser } \\
\text { Diğer }\end{array}$ & $\begin{array}{l}183(78.5) \\
50(21.5)\end{array}$ \\
\hline $\begin{array}{l}\text { Derece } \\
\text { İyi diferansiye } \\
\text { Orta derecede diferansiye } \\
\text { Undiferansiye }\end{array}$ & $\begin{array}{l}29(12.4) \\
125(53.6) \\
79(33.9)\end{array}$ \\
\hline $\begin{array}{l}\text { Lenfovasküler invazyon } \\
\text { Var } \\
\text { Yok }\end{array}$ & $\begin{array}{l}147(63.1) \\
86(36.9)\end{array}$ \\
\hline $\begin{array}{l}\text { Perinöral invazyon } \\
\text { Var } \\
\text { Yok }\end{array}$ & $\begin{array}{l}123(52.8) \\
110(47.2)\end{array}$ \\
\hline $\begin{array}{l}\text { Adjuvan kemoterapi } \\
\text { Var } \\
\text { Yok }\end{array}$ & $\begin{array}{l}181(77.7) \\
52(22.3)\end{array}$ \\
\hline $\begin{array}{l}\text { Kemoterapi Rejimi } \\
\text { FUFA } \\
\text { ECX } \\
\text { Xelox/Folfox } \\
\text { FLOT }\end{array}$ & $\begin{array}{l}102(43.8) \\
26(11.1) \\
44(18.9) \\
9(3.9)\end{array}$ \\
\hline $\begin{array}{l}\text { Adjuvan radyoterapi } \\
\text { Var } \\
\text { Yok }\end{array}$ & $\begin{array}{l}143(61.4) \\
90(38.6)\end{array}$ \\
\hline $\begin{array}{l}\text { Neoadjuvan kemoterapi } \\
\text { Var } \\
\text { Yok }\end{array}$ & $\begin{array}{l}44(18.9) \\
189(81.1)\end{array}$ \\
\hline $\begin{array}{l}\text { Definitif kemoradyoterapi } \\
\text { Var } \\
\text { Yok }\end{array}$ & $\begin{array}{l}8(3.4) \\
225(96.6)\end{array}$ \\
\hline $\begin{array}{l}\text { pN kategorisi } \\
\text { pN0 } \\
\text { pN1 } \\
\text { pN2 } \\
\text { pN3 }\end{array}$ & $\begin{array}{l}79(33.9) \\
90(38.6) \\
41(17.6) \\
23(9.9)\end{array}$ \\
\hline
\end{tabular}

FUFA: 5-FU (Fluorourasil) ve Folinik Asit, ECX: Epirubisin, Sisplatin, Kapesitabin, Xelox: Kapesitabin, Oksaliplatin, Folfox: Folinik asit, Fluorourasil, Oksaliplatin, FLOT: Fluorourasil, Lökovorin, Oksaliplatin, Dosetaksel. pN: bölgesel lenf düğümlerinin patolojik değerlendirilmesi.

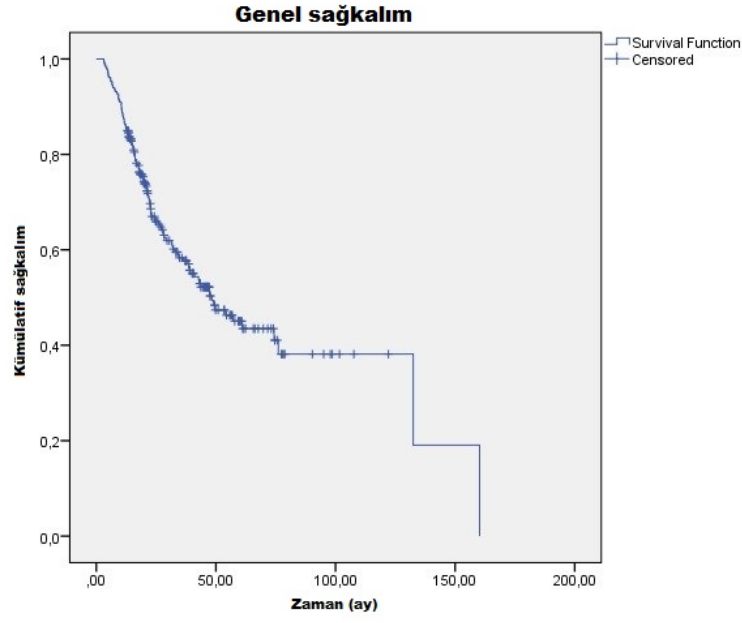

Şekil 1.

Tüm hasta grubunun genel sağkalım analizi (Kaplan-Meier ĕgrisi).

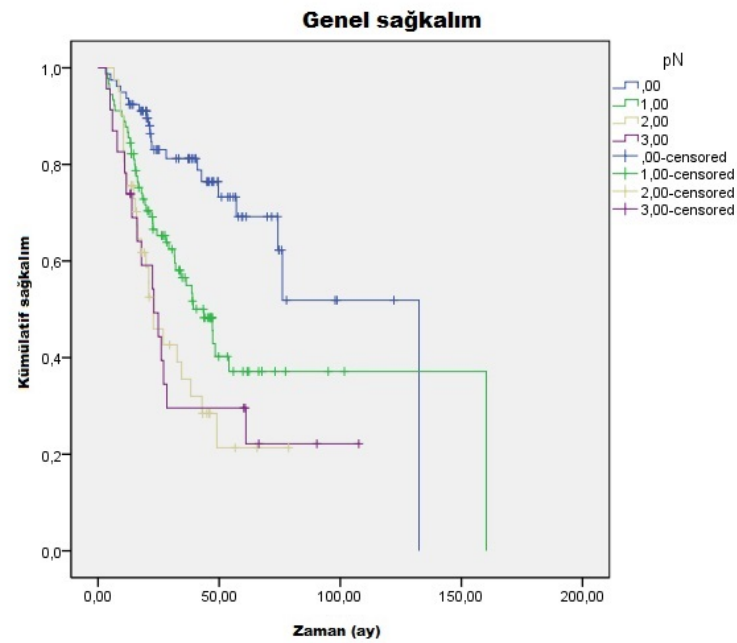

Şekil 2.

$p N$ sinıflandırmasına göre hasta gruplarının genel sağkalım analizi (Kaplan-Meier ĕgrisi).

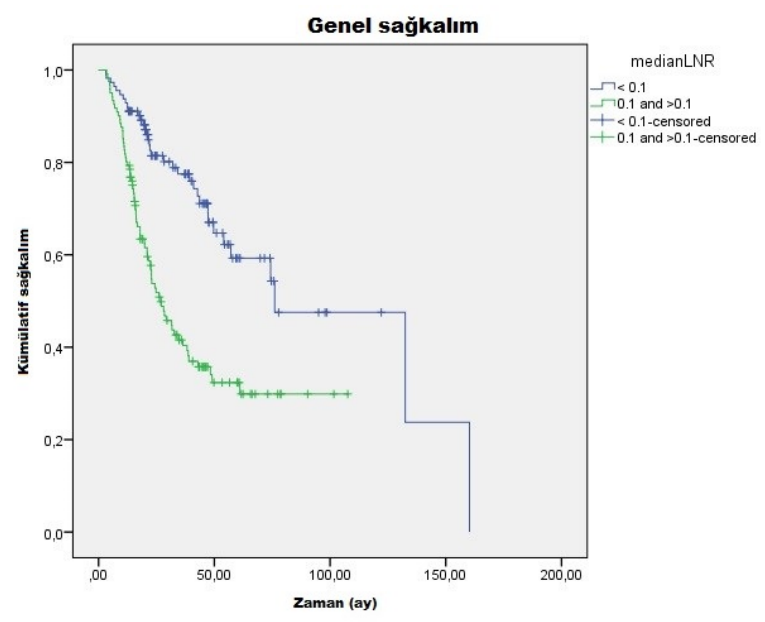

Şekil 3.

LNO sinıflandırmasina göre hasta gruplarının genel sağkalım analizi (Kaplan-Meier ĕgrisi). 
Tablo II. Genel sağkalımı etkileyen değişkenlerin tek değişkenli analizi

\begin{tabular}{|c|c|c|}
\hline \multirow[t]{2}{*}{ Değişkenler } & \multicolumn{2}{|c|}{ Genel sağkalım } \\
\hline & $P$ değeri & $\mathrm{OO}(\% 95 \mathrm{GA})$ \\
\hline $\begin{array}{l}\text { Yaş } \\
(<61 / \geq 61)\end{array}$ & 0.47 & $0.87(0.59-1.27)$ \\
\hline $\begin{array}{l}\text { Cinsiyet } \\
\text { (Kadın/Erkek) }\end{array}$ & 0.043 & $0.64(0.41-0.98)$ \\
\hline $\begin{array}{l}\text { Histolojik tip } \\
\text { (Adenokarsinom/Diğer) }\end{array}$ & 0.20 & $1.32(0.86-2.04)$ \\
\hline LVi & $<0.001$ & $0.57(0.45-0.72)$ \\
\hline $\begin{array}{l}\text { PNi } \\
\text { (Var/Yok) }\end{array}$ & $<0.001$ & $0.62(0.51-0.77)$ \\
\hline $\begin{array}{r}\text { Medyan LNO } \\
(<0.1 / \geq 0.1)\end{array}$ & $<0.001$ & $0.61(0.49-0.75)$ \\
\hline
\end{tabular}

OO: Olasılık oranı, \%95 GA: \%95 Güven aralığı, LVİ: Lenfovasküler invazyon; PNI: Perinöral invazyon; LNO: Lenf nodu oran1.

Tablo III. Genel sağkalımı etkileyen farklı değişkenlerin çok değiş̧kenli analizi

\begin{tabular}{|c|c|c|}
\hline \multirow[t]{2}{*}{ Değişkenler } & \multicolumn{2}{|c|}{ Genel sağkalım } \\
\hline & $P$ değeri & 00 (\%95 GA) \\
\hline $\begin{array}{l}\text { Cinsiyet } \\
\text { (Kadın/Erkek) }\end{array}$ & 0.06 & $0.81(0.65-1.01)$ \\
\hline $\begin{array}{l}\text { LVi } \\
\text { (Var/Yok) }\end{array}$ & 0.02 & $0.72(0.54-0.96)$ \\
\hline \begin{tabular}{|l} 
PNI \\
(Var/Yok)
\end{tabular} & 0.07 & $0.79(0.62-1.02)$ \\
\hline $\begin{array}{r}\text { Medyan LNO } \\
(<0.1 / \geq 0.1)\end{array}$ & $<0.001$ & $0.67(0.55-0.83)$ \\
\hline
\end{tabular}

OO: Olasılık oranı, \%95 GA: \%95 Güven aralığı, LVI: Lenfovasküler invazyon; PNI: Perinöral invazyon; LNO: Lenf nodu oranı.

\section{Tartışma ve Sonuç}

1997 ve 2002 yılında Uluslararası Kanserle Mücadele Birliği (UICC) ve AJCC, lenf nodu tutulumu kategorisinin metastatik lenf nodu sayısına göre sinıflandırılmasını önermiştir ${ }^{3,15}$. Bunun başlıca nedeni, metastatik lenf nodu sayısının, metastatik lenf nodlarının konumuna göre daha duyarlı olduğunu gösteren çalışmalardir ${ }^{16-18}$. Bununla birlikte, en az 15 lenf nodunun çıkarılması TNM sınıflandırması için bir ön koşuldur. Disseke olan lenf nodunun sayısı arttıkça metastatik lenf nodunun artma olasılığı mevcuttur. Ayrıca bir lenf nodunun artması veya azalmas1 $\mathrm{pN}$ kategorisini değiştirmektedir. $\mathrm{Bu}$ duruma evre migrasyonu (state migration) denilmektedir. Rezeke edilen lenf nodu sayısı arttıkça evre migrasyonu artmakta ve bu oranın\% 5 ile\% 15 arasında değiştiği bildirilmektedir ${ }^{19}$.

GK'nın diğer sınıflandırma sistemi, yani JGCC sınıflandırması hakkında bir dizi farklı görüş önerilmiş̧ir.
Batı ülkelerinden yapılan çalışmalar, D2 lenfadenektominin sağkalımda bir rolü olmadığını, morbidite ve mortaliteyi artırdığını göstermiştir. Ancak tam tersine, Doğu ülkelerinden bildirilen çalışmalarda sağkalımı iyileştirdiği öne sürülmektedir ${ }^{20-22}$.

LNO, birçok araştırmacı tarafindan yeni bir prognostik faktör olarak önerilmiştir $(7,9,19)$. Örneğin, Yu ve ark. LNO'nun, metastatik lenf nodlarının N0 (metastaz yok), N1 (disseke lenf nodlarının \%1 ila 25'inde metastaz) ve N2 (disseke lenf nodlarının $>\% 25$ 'inde metastaz) temelinde kategorizasyondan sonra cerrahinin sonucunu tahmin etmek için basit, pratik ve tekrarlanabilir bir araç olabileceğini ifade etmiștir ${ }^{23}$. Diğer çalışmalara benzer şekilde Bando ve ark., D2 lenf nodu diseksiyonu ile küratif gastrektomi yapılan toplam 650 hasta arasinda LNO'yu 3 grupta kategorize etmiş $(0=$ nodal metastaz yok, metastatik lenf nodlarının oranına göre $1=0-0.1,2=0.1-0.25$ ve $3=\geq 0.25$ ) ve grup 3 için anlamlı sağkalım farkı bulmuş ve Japon sınıflamasının, TNM ve LNO'nun bağımsız prognostik faktörler olduğunu bildirmişlerdir ${ }^{7}$. Inoue ve ark. tarafindan yapılan çalışmada ise R0 rezeksiyonu ve D2 lenf nodu diseksiyonu yapılan 474 hastada, LNO en anlamlı prognostik faktör olarak bulunmuştur ${ }^{8}$. Bu hasta grubundaki çoğu çalışmada LNO sınıflandırması için önceden tanımlanmış $\mathrm{N}$ oranı kategorileri (yani $\% 10, \% 25$ ve \%50) kullanılmıştır. Sadece birkaç çalışmada, LNO'nun sağkalımdaki rolü üzerine prognostik analizle birlikte $\% 11$, \%37 veya $\% 20$ gibi tek bir kesme değeri bildirmiştir ${ }^{24-26}$. Bizim çalışmamızda da, literatürdeki çoklu kesme noktası olan çoğu çalışmadan farklı olarak, tek bir kesme noktası alınarak, medyan LNO üzerinden analiz gerçekleștirilmiștir. Bulgularımız, literatür ile uyumlu olarak, LNO'nun genel sağkalım için bağımsız bir prognostik değere sahip olduğunu desteklemektedir.

Tek bir kesme değerini tanımlayan bir çalışmada, opere edilen GK hastalarında LNO için \%11'lik bir kesme değeri kullanılmış ve bu değere dayanan analizde, sırası ile $\mathrm{LNO} \geq \% 11$ ve $<\% 11$ grupları için için 14 ve 58 aylık bir medyan GS göstermiştir. İleri yaş, total gastrektomi ve daha geniş rezeksiyon ihtiyacı diğer anlamlı negatif prediktörler olarak gösterilmiştir $^{25}$. Bizim çalışmamizda da medyan LNO değeri, benzer olarak \%10 hesaplanmıştır. LNO $<0.1$ olan grupta medyan GS 76 ay, $\mathrm{LNO} \geq 0.1$ olan grupta ise medyan GS 26.9 ay saptanmış olup, bu fark istatistiksel olarak anlamlı idi. GS ile yaşın arasında ilişkisi olmadı̆̆ı, cinsiyetin ise ilişkili olduğu gösterildi. Bu çalışmaya kıyasla, benzer kesme değerine rağmen, çalışmamızda sağkalım oranlarımız daha yüksekti. Yine çalışmamız ve bu çalışma arasında medyan yaş ve cinsiyet dağılımı benzerdi ve bu çalışmada evre dağılımı bildirilmemesine rağmen, bizim çalışmamızda çok sayıda Evre III hasta vardı. Yazarlar çalışmalarunda sadece en az 15 disseke lenf nodu olan hastaların dahil edildiğini belirtmişlerdir. Öte yandan, bizim 


\section{Mide Kanserinde Pozitif Lenf Nodu Oranı}

çalışmamızda lenf nodu diseksiyonu olan daha heterojen bir hasta grubuna rağmen, sadece R0 hastalarının (yani cerrahi sınır negatif) dahil edilmiş olması ve adjuvan tedavi alan hasta oranının fazla olmasının, bu GS farklılığına katkısı olduğunu düşünüyoruz.

D2 lenf nodu diseksiyonu olan 44 hastada, tek bir kesme değeri değeri bildiren başka bir çalışmada, hastalar \%37'lik bir LNO’ya göre kategorize edilmiş, LNO yüksek olan grup, 1 yıllık genel ve hastalıksız sağkalım açısından daha kötü saptanmıştır. Diğer faktörler (yaş, cinsiyet, histoloji, tümör derinliği, LVİ ve PNI) genel ve hastalıksız sağkalım açısından bağımsız bir prediktör olarak belirlenememiştir ${ }^{24}$. Bizim çalışmamızda ise D1-3 disseke lenf nodu olan GK'lı hastalarda tek kesme değeri ile yapılan bir analizde, LNO'nun yanısıra LVİ ile de sağkalım arasında anlamlı ilişkili bulunmuştur.

GK hastalarını içeren bazı çalışmalar, lenf nodu oranının GS açısından ${ }^{27}$ lenf nodu sayısından daha üstün olduğunu bildirmesine rağmen, literatürdeki tartışma en uygun nodal sinıflamanın yanı sıra LNO'ya göre lenf nodu sayısının göreceli önemi üzerinde devam etmektedir $^{28}$. Son yıllarda, özellikle sinırlı lenf nodu diseksiyonu olan hastalarda LNO, geleneksel N evrelemesine bir alternatif olarak değerlendirilmekte$\operatorname{dir}^{14,29,30}$.

Bu çalışmanın birincil amacı, LNO'nun pN üzerindeki üstünlüğünü göstermek değil, daha önce LNO'nun halihazırda yerleşik prognostik göstergelere ek olarak sağkalımı tahmin etmek için yeni ve pratik bir parametre olup olmadığını incelemekti. Bununla birlikte, heterojen bir lenf nodu diseksiyonu grubunun dahil edilmesi; hastaların aldığı adjuvan kemoterapi rejimleri farklı olduğundan, tedavi farklılığına göre analiz yapılamamış olmasi; veri eksiklikleri nedeni ile hastaların ne kadarının tedaviyi tamamladığının bilinememesi; çalışmamızın retrospektif tasarımı ve relaps/nüks verilerinin olmaması nedeni ile hastalıksız sağkalım analizinin yapılamamış olması çalışmamızın önemli kısıtlılıklarıdır.

Sonuç olarak, bulgularımız LNO ve pN sınıflandırma sistemlerinin GK için radikal rezeksiyon uygulanan bir grup hastada GS'nin bağımsız prediktörleri olduğunu göstermiştir. Mevcut kılavuzlar 1şı ğında, anatomik konum izin veriyorsa ve sayı temelli $\mathrm{N}$ evrelemesi mümkünse, lenf nodu metastazı için genişletilmiş bir lenf nodu diseksiyonu yapılması önerilebilir. Bununla birlikte, disseke lenf nodlarının sayısı 15 'ten azsa veya D1 diseksiyonu durumunda, klinisyenin taraflılığını veya hatasını en aza indirmek için LNO kullanılabilir. Öte yandan, LNO'yu patolojik sınıflandırma sistemlerine dahil etmek veya halihazırda yerleşik sistemler üzerindeki üstünlüğünü göstermek için prospektif ve randomize çalışmaların yapılması gerekmektedir.
Etik Kurul Onay Bilgisi:

Onaylayan Kurul: Sağlık Bilimleri Üniversitesi Erzurum Bölge Eğitim ve Araştırma Hastanesi Klinik Araştırmalar Etik Kurulu.

Onay Tarihi: 20.05 .2020

Karar No: 37732058-514.10

\section{Kaynaklar}

1. Bray F, Ferlay J, Soerjomataram I, ve ark. Global cancer statistics 2018: GLOBOCAN estimates of incidence and mortality worldwide for 36 cancers in 185 countries. CA Cancer J Clin 2018; 68:394-424.

2. Hartgrink HH, Jansen EP, vanGrieken NC ve VandeVelde CJ. Gastric cancer. Lancet 2009; 374:477-490

3. Japanese Gastric Cancer Association. Japanese Classification of Gastric Carcinoma-2nd English Edition. Gastric Cancer 1998; 1: $10-24$.

4. Ajani JA, In H, Sano T, ve ark. Stomach. In: AJCC CancerStaging Manual, 8th ed. Amin MB (Ed). AJCC, Chicago, 2017; 203.

5. Kwon SJ ve Kim GS: Prognostic significance of lymph node metastasis in advanced carcinoma of the stomach. Br J Surg 1996;83:1600-3.

6. Kim JP, Lee JH, Kim SJ, ve ark. Clinicopathologic characteristics and prognostic factors in 10,783 patients with gastric cancer. Gastric Cancer 1998; 1:125-33.

7. Bando E, Yonemura Y, Taniguchi K, ve ark. Outcome of ratio of lymph node metastasis in gastric carcinoma. Ann Surg Oncol 2002;9:775-84.

8. Inoue $\mathrm{K}$, Nakane $\mathrm{Y}$, liyama $\mathrm{H}$, ve ark. The superiority of ratiobased lymph node staging in gastric carcinoma. Ann Surg Oncol 2002; 9:27-34.

9. Kodera Y, Yamamura Y, Shimizu Y, ve ark. Metastatic gastric lymph node rate is a significant prognostic factor for resectable stage IV stomach cancer. J Am Coll Surg 1997; 185:65-9.

10. Hyung WJ, Noh SH, Yoo $\mathrm{CH}$, ve ark. Prognostic significance of metastatic lymph node ratio in T3 gastric cancer. World J Surg 2002; 26:323-9.

11. Marchet A, Mocellin S, Ambrosi A, ve ark. The prognostic value of N-ratio in patients with gastric cancer: validation in a large, multicenter series. Eur J Surg Oncol 2008; 34: 159-165

12. Rodríguez Santiago JM, Muñoz E, Martí M, ve ark. Metastatic lymph node ratio as a prognostic factor in gastric cancer. Eur J Surg Oncol 2005; 31: 59-66

13. Kunisaki C, Shimada H, Nomura M, ve ark. Clinical impact of metastatic lymph node ratio in advanced gastric cancer. Anticancer Res 2005; 25:1369-75.

14. Celen O, Yildirim E ve Berberoglu U: Prognostic impact of positive lymph node ratio in gastric carcinoma. J Surg Oncol 2007; 96:95-101.

15. Sobin LH ve Wittekind CH. International Union Against Cancer (UICC). TNM Classification of Malignant Tumours. 5th ed. New York: Wiley, 1997.

16. Roder JD, Böttcher K, Busch R, ve ark. Classification of regional lymph node metastasis from gastric carcinoma. German Gastric Cancer Study Group. Cancer 1998; 82: 621-631

17. Ichikura T, Tomimatsu S, Uefuji K, ve ark. Evaluation of the New American Joint Committee on Cancer/International Union against cancer classification of lymph node metastasis from gastric carcinoma in comparison with the Japanese classification. Cancer 1999; 86: 553-558

18. Saito H, Fukumoto Y, Osaki T, ve ark. Prognostic significance of level and number of lymph node metastases in patients with gastric cancer. Ann Surg Oncol 2007; 14: 1688-1693 


\section{F. Yalçın Müsri, ark.}

19. Nitti D, Marchet A, Olivieri M, ve ark. Ratio between metastatic and examined lymph nodes is an independent prognostic factor after D2 resection for gastric cancer: analysis of a large European monoinstitutional experience. Ann Surg Oncol 2003;10:1077-85.

20. Hartgrink HH, van de Velde CJ, Putter H, ve ark. Extended lymph node dissection for gastric cancer: who may benefit? Final results of the randomized Dutch gastric cancer group trial. J Clin Oncol 2004; 22:2069-2077.

21. Cuschieri A, Weeden S, Fielding J, ve ark. Patient survival after D1 and D2 resections for gastric cancer: long-term results of the MRC randomized surgical trial. Surgical Co-operative Group. Br J Cancer 1999; 79:1522-1530.

22. Wu CW, Hsiung CA, Lo SS, ve ark. Nodal dissection for patients with gastric cancer: a randomised controlled trial. Lancet Oncol 2006; 7:309-315.

23. Yu W, Choi GS, Whang I, ve ark. Comparison of five systems for staging lymph node metastasis in gastric cancer. Br J Surg 1997; 84:1305-9.

24. Attaallah W, Uprak K, Gunal Ö, ve ark. Prognostic Impact of the Metastatic Lymph Node Ratio on Survival in Gastric Cancer Indian J Surg Oncol 2016; 7(1):67-72.
25. Wohnrath DR, Araujo RLC. Positive node-ratio in curativeintent treatment for gastric cancer is a strong independent prognostic factor for 5-year overall survival. J Surg Oncol 2020;121(5):777-783.

26. Siewert JR, Bottcber FK, Stein HJ, ve ark. Relevant prognostic factors in gastric cancer: ten-year results of the German Gastric Cancer Study. Ann Surg 1998; 228:449-61.

27. Wu HL, Tian Q, Peng CW, ve ark. Multivariate survival and outcome analysis of 154 patients with gastric cancer at a single Chinese institution. Asian Pac J Cancer Prev 2011; 12:33413345

28. Lee SY, Hwang I, Park YS, ve ark. Metastatic lymph node ratio in advanced gastric carcinoma: a better prognostic factor than number of metastatic lymph nodes? Int J Oncol 2010; 36(6): 1461-1467

29. Marchet A, Mocellin S, Ambrosi A, ve ark. The ratio between metastatic and examined lymph nodes ( $\mathrm{N}$ ratio) is an independent prognostic factor in gastric cancer regardless of the type of lymphadenectomy. Ann Surg 2007; 245:543-552

30. Liu C, Lu P, Lu Y, ve ark. Clinical implications of metastatic lymph node ratio in gastric cancer. BMC Cancer 2007; 7:200 